\title{
Subject Index to Volume $23-1996$
}

\section{ABSCESS}

Stereotactic Management of Bacterial Brain Abscesses 34 (FEB)

ABSTRACTS

35th Annual Meeting of the Canadian Association of Neuropathologists 149 (MAY)

31 st Meeting of the Canadian Congress of Neurological Sciences (Supplement 1)

ADDISON'S DISEASE

Addison's Disease Presenting with Cerebral Edema 141 (MAY)

\section{ALZHEIMER DISEASE}

Prior Intra-operative Hypotension is not a Risk Factor for Development of Alzheimer's Disease 57 (FEB)

\section{ANEURYSMS}

Acute Hydrocephalus Following Aneurysmal Subarachnoid Hemmorrhage 40 (FEB)

Epidemiological Study of Ruptured Intracranial Aneurysms in the Saguenay-Lac-Saint-Jean region (Quebec. Canada) 184 (AUG)

\section{ASTROCYTOMAS}

Pre-radiation Chemotherapy for Malignant Glioma in Adults 123 (MAY)

Focal Midbrain Glioma: Long Term Survival in a Cohort of 16 Patients and the Implications for Management 204 (AUG)

Calmodulin Dependent Cyclic Nucleotide Phosphodiesterase in Human Cerebral Cortex and Glioblastoma Multiforme 245 (NOV)

Postirradiated and Nonirradiated Gliosarcoma: Immunophenotypical Profile 251 (NOV)

ATAXIA

Kinematics of Initiating a Two-Joint Arm Movement in Patients with Cerebellar Ataxia 3 (FEB)

\section{ATTENTION}

A Normal Bias Toward a Pictorially Defined Top in Line Bisection 110 (MAY)

\section{BABINSKI, JOSEPH}

On The Names of Babinski 76 (FEB)

\section{BLOOD-BRAIN BARRIER}

The Efficacy of Retrograde Infusion with LY231617 in a Rat Middle Cerebral Artery Occlusion Model 175 (AUG)

BOTULINUM TOXIN

Localizing Muscles for Botulinum Toxin Treatment of Focal Hand Dystonia 195 (AUG)

\section{BRAIN ABCESS}

Abscess Within a Brain Metastasis 300 (NOV)

BRAIN TUMOURS

Epidemiology of Childhood Brain Tumors 118 (MAY)

Add-on Gabapentin for Refractory Seizures in Patients With Brain Tumours 128 (MAY)

Abscess Within a Brain Metastasis 300 (NOV)

\section{CAUDA EQUINA}

Hemi-Cauda Equina Syndrome from Herniated Lumbar Disc: a Neurosurgical Emergency? 296 (AUG)
CEREBELLAR INCOORDINATION

Kinematics of Initiating a Two-Joint Arm Movement in Patients with Cerebellar Ataxia 3 (FEB)

\section{CEREBRAL BLOOD FLOW}

The Efficacy of Retrograde Infusion with LY231617 in a Rat Middle Cerebral Anery Occlusion Model 175 (AUG)

\section{CEREBRAL EDEMA}

Tirilazad Prevention of Reperfusion Edema After Focal Ischemia in Cynomologus Monkeys 46 (FEB)

Addison's Disease Presenting with Cerebral Edema 141 (MAY)

\section{CEREBROVASCULAR DISEASE}

Acute Hydrocephalus Following Aneurysmal Subarachnoid Hemmorthage 40 (FEB)

Symptomatic Dystonias Associated with Structural Brain Lesions: Report of 16 Cases 53 (FEB)

The Efficacy of Retrograde Infusion with LY231617 in a Rat Middle Cerebral Artery Occlusion Model 175 (AUG)

Epidemiological Study of Ruptured Intracranial Aneurysms in the Saguenay-Lac-Saint-Jean region (Quebec, Canada) 184 (AUG)

Headache and Scalp Edema in Sickle Cell Disease 224 (AUG)

\section{CHEMOTHERAPY}

Pre-radiation Chemotherapy for Malignant Glioma in Adults 123 (MAY)

\section{CHONDROMA}

Intracranial Chondroma. Report of Two Cases and Review of the Literature I32 (MAY)

COMA

Triphasic Waves During Post-Ictal Stupor 208 (AUG)

DEMENTIA

A Novel Approach to the Determination and Characterization of HIV Dementia 104 (MAY)

\section{DISC HERNIATION}

Hemi-Cauda Equina Syndrome from Herniated Lumbar Disc: a Neurosurgical Emergency? 296 (AUG)

\section{DOPAMINE MECHANISMS}

Risk Factors for Peak Dose Dyskinesia in 100 Levodopa-treated Parkinsonian Patients 189 (AUG)

Impaired Incentive Learning in Treated Parkinson's Disease 271 (NOV)

\section{DOPAMINERGIC DRUGS}

Risk Factors for Peak Dose Dyskinesia in 100 Levodopa-treated Parkinsonian Patients 189 (AUG)

Perioperative Problems in Parkinson's Disease and Their Management: apomorphine with rectal domperidone 198 (AUG)

Impaired Incentive Learning in Treated Parkinson's Disease 271 (NOV)

Descriptive Epidemiology of Parkinson's Disease through Proxy Measures 279 (NOV)
DYSTONIA

Symptomatic Dystonias Associated with Structural Brain Lesions: Report of 16 Cases 53 (FEB)

Localizing Muscles for Botulinum Toxin Treatment of Focal Hand Dystonia 195 (AUG)

Relationship Between Sleep, Neck Muscle Activity, and Pain in Cervical Dystonia 285 (NOV)

EDITORIAL

Manganese: the Controversial Metal. At What Levels Can Deleterious Effects Occur? 93 (MAY)

\section{ELECTROENCEPHALOGRAPHY}

Excitation and Inhibition in Epilepsy 167 (AUG) Triphasic Waves During Post-lctal Stupor 208 (AUG)

\section{ELECTROMYOGRAPHY}

Localizing Muscles for Botulinum Toxin Treatment of Focal Hand Dystonia 195 (AUG)

\section{ENCEPHALOPATHY}

Blood Manganese Correlates with Brain Magnetic Resonance Imaging Changes in Patients with Liver Disease 95 (MAY)

\section{EPENDYMOMA}

Narcolepsy Secondary to Fourth Ventricular Subependymoma 59 (FEB)

\section{EPIDEMIOLOGY}

Epidemiology of Childhood Brain Tumors 118 (MAY)

Epidemiological Study of Ruptured Intracranial Aneurysms in the Saguenay-Lac-Saint-Jean region (Quebec, Canada) 184 (AUG)

Descriptive Epidemiology of Parkinson's Disease through Proxy Measures 279 (NOV)

The Occurrence of Multiple Sclerosis in the Hutterites of North America 291 (NOV)

\section{EPILEPSY}

George A. Savoy, Visionary Benefactor of Canadians with Epilepsy, and the History of the Savoy Foundation for Epilepsy 80 (FEB)

Post-traumatic Frontal Lobe Epilepsy with Structural Changes: Excellent Results After Cortical Resection 114 (MAY)

Add-on Gabapentin for Refractory Seizures in Patients With Brain Tumours 128 (MAY)

Excitation and Inhibition in Epilepsy 167 (AUG)

Triphasic Waves During Post-Ictal Stupor 208 (AUG)

Functional MRI Localization of Language in a 9Year-Old Child 213 (AUG)

Historical Vignette: Cerebral Cortical Stimulation and Surgery for Epilepsy 303 (NOV)

Vigabatrin S13 (Supplement 2)

Antiepileptic Drugs - Current Use S18 (Supplement 2)

Quality of Life Measurements in Epilepsy S3 (Supplement 2)

Lamotrigine - An Update S6 (Supplement 2)

\section{FUNCTIONAL MRI}

Functional MRI Localization of Language in a 9 Year-Old Child 213 (AUG) 


\section{GABAPENTIN}

Add-on Gabapentin for Refactory Seizures in Patients With Brain Tumours 128 (MAY)

GENETICS - CLINICAL

Epidemiological Study of Ruptured Intracranial Aneurysms in the Saguenay-Lac-Saint-Jean region (Quebec, Canada) 184 (AUG)

The Occurrence of Multiple Sclerosis in the Hutterites of North America 291 (NOV)

\section{GLIOMA}

Focal Midbrain Glioma: Long Term Survival in a Cohort of 16 Patients and the Implications for Management 204 (AUG)

H-REFLEX

A Measure of Peripheral Nerve Stimulation Efficacy Applicable to H-Reflex Studies 264 (NOV)

\section{H-REFLEX MODULATION}

Reciprocal Inhibition in Hemiplegic: Correlation with Clinical Features and Recovery 15 (FEB)

\section{HEAD TRAUMA}

Post-traumatic Frontal Lobe Epilepsy with Structural Changes: Excellent Results After Cortical Resection 114 (MAY)

Bilateral Hypoglossal Nerve Injury with Occipital Condylar Fracture 145 (MAY)

HEADACHE

Headache and Scalp Edema in Sickle Cell Disease 224 (AUG)

HEALTH RELATED OUALITY OF LIFE

Measurement of Health-Related Quality of Life in Multiple Sclerosis Patients 99 (MAY)

HEMIPLEGIA

Reciprocal Inhibition in Hemiplegic: Correlation with Clinical Features and Recovery 15 (FEB)

HISTORY

A History of Neurology in Toronto: Part 1163 (FEB)

On The Names of Babinski 76 (FEB)

Historical Vignette: Cerebral Cortical Stimulation and Surgery for Epilepsy 303 (NOV)

HUMAN IMMUNODEFICIENCY VIRUS

A Novel Approach to the Determination and Characterization of HIV Dementia 104 (MAY)

\section{HYDROCEPHALUS}

Acutc Hydrocephalus Following Aneurysma Subarachnoid Hemmorrhage 40 (FEB)

\section{HYPOGLOSSAL NERVE}

Bilateral Hypoglossal Nerve Injury with Occipital Condylar Fracture 145 (MAY)

\section{HYPOTENSION}

Prior Intra-operative Hypotension is not a Risk Factor for Development of Alzheimer's Disease 57 (FEB)

IDIOPATHIC INTRACRANIAL

Addison's Disease Presenting with Cerebral Edema 141 (MAY)

INFECTIOUS DISEASES

Stereotactic Management of Bacterial Brain Abscesses 34 (FEB)

Listeria Spinal Cord Abscess - Clinical and MRI Findings 220 (AUG)

Abscess Within a Brain Metastasis 300 (NOV)

\section{JASPER, HERBERT}

Herbert Jasper: an Appreciation and a Tribute on His 90th Birthday 308 (NOV)
LAMOTRIGINE

Lamotrigine - An Update S6 (Supplement 2)

LANGUAGE

Functional MRI Localization of Language in a 9Year-Old Child 213 (AUG)

LINE BISECTION

A Normal Bias Toward a Pictorially Defined Top in Line Bisection 110 (MAY)

LISTERIA MONOCY'TOGENES

Listeria Spinal Cord Abscess - Clinical and MRI Findings 220 (AUG)

LITTLE, JOHN MASON

Historical Vignette: Cerebral Cortical Stimulation and Surgery for Epilepsy 303 (NOV)

LIVER DISEASE

Blood Manganese Correlates with Brain Magnetic Resonance Imaging Changes in Patients with Liver Disease 95 (MAY)

LYMPHOMA

Paraneoplastic Limbic Encephalitis in Hodgkin's Disease 138 (MAY)

\section{MAGNETIC RESONANCE IMAGING}

Blood Manganese Correlates with Brain Magnetic Resonance Imaging Changes in Patients with Liver Disease 95 (MAY)

Listeria Spinal Cord Abscess - Clinical and MRI Findings 220 (AUG)

MANGANESE

Manganese: the Controversial Metal. At What Levels Can Deleterious Effects Occur? 93 (MAY)

Blood Manganese Correlates with Brain Magnetic Resonance Imaging Changes in Patients with Liver Disease 95 (MAY)

\section{MEMORY}

Paraneoplastic Limbic Encephalitis in Hodgkin's Disease 138 (MAY)

\section{MOVEMENT DISORDERS}

Symptomatic Dystonias Associated with Structural Brain Lesions: Report of 16 Cases 53 (FEB)

Risk Factors for Peak Dose Dyskinesia in 100 Levodopa-treated Parkinsonian Patients 189 (AUG)

MULTIPLE SCLEROSIS

Measurement of Health-Related Quality of Life in Multiple Sclerosis Patients 99 (MAY)

The Occurrence of Multiple Sclerosis in the Hutterites of North America 29l (NOV)

NARCOLEPSY

Narcolepsy Secondary to Fourth Ventricular Subependymoma 59 (FEB)

NEGLECT

A Normal Bias Toward a Pictorially Defined Top in Line Bisection 110 (MAY)

\section{NERVE CONDUCTION}

A Measure of Peripheral Nerve Stimulation Efficacy Applicable to H-Reflex Studies 264 (NOV)

\section{NEURO-ONCOLOGY}

Symptomatic Dystonias Associated with Structural Brain Lesions: Report of 16 Cases 53 (FEB)

Epidemiology of Childhood Brain Tumors 118 (MAY)
Pre-radiation Chemotherapy for Malignant Glioma in Adults 123 (MAY)

Add-on Gabapentin for Refractory Seizures in Patients With Brain Tumours 128 (MAY)

Intracranial Chondroma. Report of 'Two Cases and Review of the Literature 132 (MAY)

Paraneoplastic Limbic Encephalitis in Hodgkin : Disease 138 (MAY)

Calmodulin Dependent Cyclic Nucleotide Phosphodiesterase in Human Cerebral Cortex and Glioblastoma Multiforme 245 (NOV)

Postirradiated and Nonirradiated Gliosarcoma: Immunophenotypical Profile 251 (NOV)

Malignant Rhabdoid Tumor of Brain: An Aggressive Clinical Entity 257 (NOV)

Abscess Within a Brain Metastasis 300 (NOV)

\section{NEUROCHEMISTRY}

Calmodulin Dependent Cyclic Nucleotide Phosphodiesterase in Human Cerebral Cortex and Glioblastoma Multiforme 245 (NOV)

\section{NEUROENDOCRINOLOGY}

Addison's Disease Presenting with Cerebral Edema 141 (MAY)

NEUROLOGICAL PRACTICE

Neurology and the Community 231 (AUG)

NEUROLOGY - BEHAVIOURAL

A Normal Bias Toward a Pictorially Defined Top in Line Bisection 110 (MAY)

\section{NEUROPATHOLOGY}

Vagal Nerve Complex in Normal Developmemt and Sudden Infant Death Syndrome 24 (FEB)

Abstracts of the $35^{\text {th }}$ Annual Mecting of the Canadian Association of Neuropathologists 149 (MAY)

Calmodulin Dependent Cyclic Nucleotide Phosphodiesterase in Human Cerebral Cortex and Glioblastoma Multiforme 245 (NOV)

Postirradiated and Nonirradiated Gliosarcona: lmmunophenotypical Profile 251 (NOV)

Malignant Rhabdoid Tumor of Brain: An Aggressive Clinical Entity 257 (NOV)

\section{NEUROPHARMACOLOGY}

Tirilazad Prevention of Reperfusion Edema After Focal Ischemia in Cynomologus Monkeys 46 (FEB)

Add-on Gabapentin for Refractory Seizures in Patients With Brain Tumours 128 (MAY)

The Efficacy of Retrograde Infusion with LY231617 in a Rat Middle Cerebral Artery Occlusion Model 175 (AUG)

Risk Factors for Peak Dose Dyskinesia in 100 Levodopa-treated Parkinsonian Patients 189 (AUG)

Vigabatrin S13 (Supplement 2)

Antiepileptic Drugs - Current Use S18 (Supplement 2)

Lamotrigine - An Update S6 (Supplement 2)

\section{NEUROPHYSIOLOGY}

Reciprocal Inhibition in Hemiplegic: Correlation with Clinical Features and Recovery 15 (FEB)

Kinematics of Initiating a Two-Joint Arm Movement in Patients with Cerebellar Ataxia 3 (FEB)

Excitation and Inhibition in Epilepsy 167 (AUG) A Measure of Peripheral Nerve Stimulation Efficacy Applicable to H-Reflex Studies 264 (NOV) 


\section{NEUROPROTECTION THERAPY}

Tirilazad Prevention of Reperfusion Edema After Focal Ischemia in Cynomologus Monkeys 46 (FEB)

NEUROPSYCHOLOGY

A Novel Approach to the Determination and Characterization of HIV Dementia 104 (MAY)

A Normal Bias Toward a Pictorially Defined Top in Line Bisection 110 (MAY)

Impaired Incentive Learning in Treated Parkinson's Disease 271 (NOV)

\section{NEURORADIOLOGY}

Post-traumatic Frontal Lobe Epilepsy with Structural Changes: Excellent Results After Cortical Resection 114 (MAY)

\section{NEUROSURGERY}

Stereotactic Management of Bacterial Brain Abscesses 34 (FEB)

Post-traumatic Frontal Lobe Epilepsy with Structural Changes: Excellent Results After Cortical Resection 114 (MAY)

Hemi-Cauda Equina Syndrome from Herniated Lumbar Disc: a Neurosurgical Emergency? 296 (AUG)

Historical Vignette: Cerebral Cortical Stimulation and Surgery for Epilepsy 303 (NOV)

\section{OCCIPITAL CONDYLE}

Bilateral Hypoglossal Nerve Injury with Occipital Condylar Fracture 145 (MAY)

PAIN

Longterm Treatment of Intractible RSD with Intrathecal Morphine 156 (MAY)

Relationship Between Sleep, Neck Muscle Activity, and Pain in Cervical Dystonia 285 (NOV)

PARANEOPLASTIC SYNDROMES

Paraneoplastic Limbic Encephalitis in Hodgkin's Disease 138 (MAY)

PARKINSON'S DISEASE

Environmental Exposures in Elderly Canadians with Parkinson's Disease 157 (MAY)

Blood Manganese Correlates with Brain Magnetic Resonance Imaging Changes in Patients with Liver Disease 95 (MAY)

Risk Factors for Peak Dose Dyskinesia in 100
Levodopa-treated Parkinsonian Patients 189 (AUG)

Perioperative Problems in Parkinson's Disease and Their Management: apomorphine with rectal domperidone 198 (AUG)

Impaired Incentive Leaming in Treated Parkinson's Disease 271 (NOV)

Descriptive Epidemiology of Parkinson's Disease through Proxy Measures 279 (NOV)

\section{PARKINSONISM}

Manganese: the Controversial Metal. At What Levels Can Deleterious Effects Occur? 93 (MAY)

PERIPHERAL NERVE

Longterm Treatment of Intractible RSD with Intrathecal Morphine 156 (MAY)

A Measure of Peripheral Nerve Stimulation Efficacy Applicable to H-Reflex Studies 264 (NOV)

PERIPHERAL NEUROPATHY

Isolated Suprascapular Nerve Palsy A Review of Nine Cases 234 (AUG)

PROGRESSIVE SUPRANUCLEAR PALSY

Environmental Exposures in Elderly Canadians with Parkinson's Disease 157 (MAY)

QUALITY OF LIFE

Quality of Life Measurements in Epilepsy S3 (Supplement 2)

\section{RADIATION ONCOLOGY}

Focal Midbrain Glioma: Long Term Survival in a Cohort of 16 Patients and the Implications for Management 204 (AUG)

Postirradiated and Nonirradiated Gliosarcoma: Immunophenotypical Profile 251 (NOV)

RHABDOID TUMOUR

Malignant Rhabdoid Tumor of Brain: An Aggressive Clinical Entity 257 (NOV)

RICHARDSON LECTURE

Neurology and the Community 231 (AUG)

SAVOY, GEORGE A.

George A. Savoy, Visionary Benefactor of Canadians with Epilepsy, and the History of the Savoy Foundation for Epilepsy 80 (FEB)

\section{SICKLE CELL DISEASE}

Headache and Scalp Edema in Sickle Cell Disease 224 (AUG)
SLEEP

Relationship Between Sleep, Neck Muscle Activity, and Pain in Cervical Dystonia 285 (NOV)

\section{SPINAL CORD}

Listeria Spinal Cord Abscess - Clinical and MRI Findings 220 (AUG)

Periodontoid Synovial Cyst Causing Cervicomedullary Compression 227 (AUG)

\section{STEREOTACTIC}

Stereotactic Management of Bacterial Brain Abscesses 34 (FEB)

\section{SUBARACHNOID HEMORRHAGE}

Acute Hydrocephalus Following Ancurysmal Subarachnoid Hemmorrhage 40 (FEB)

SUDDEN INFANT DEATH SYNDROME

Vagal Nerve Complex in Normal Developmemt and Sudden Infant Death Syndrome 24 (FEB)

\section{SURGICAL COMPLICATIONS}

Perioperative Problems in Parkinson's Disease and Their Management: apomorphine with rectal domperidone 198 (AUG)

SYNOVIAL CYST

Periodontoid Synovial Cyst Causing Cervicomedullary Compression 227 (AUG)

TORONTO

A History of Neurology in Toronto: Part Il 63 (FEB)

\section{TOXICOLOGY}

Environmental Exposures in Elderly Canadians with Parkinson's Disease 157 (MAY)

TRAUMA

Isolated Suprascapular Nerve Palsy: A Review of Nine Cases 234 (AUG)

\section{VAGUS NERVE}

Vagal Nerve Complex in Normal Developmemt and Sudden Infant Death Syndrome 24 (FEB)

\section{VIGABATRIN}

Vigabatrin \$13 (Supplement 2)

\section{VIROLOGY}

A Novel Approach to the Determination and Characterization of HIV Dementia 104 (MAY) 